\title{
Pengaruh Tegangan Pompa Bahan Bakar Terhadap Kandungan Emisi Gas Buang
}

\author{
Fuel Pump Voltage Effect On Exhaust Emissions
}

\author{
Mufdi Ashadrul Aldi Pane, Wakhinuddin S, Dwi Sudarno Putra \& M Nasir \\ Jurusan Teknik Otomotif Universitas Negeri Padang Email : mufdialdi@gmail.com, \\ wakhid_nuddin@yahoo.com,dwisudarnoputra@gmail.com \& achin@yahoo.com
}

\begin{abstract}
Combustion emissions from millions of exhaust coming out every day would cause problems because the impact on the air quality and the problems of chronic diseases when inhaled by humans. This study wants to reveal the influence of variations in electric voltage to the fuel pump exhaust emissions. The study was conducted using an experimental method, using a form of Post-test Only Control Design. The object being tested is a Toyota Avanza $1.3 \mathrm{GM} / \mathrm{T}$. The voltage should be $12 \mathrm{~V}$, the research varying the voltage to the level of $11 \mathrm{~V}, 10 \mathrm{~V}$ and $9 \mathrm{~V}$. The results obtained, when the voltage is $12 \mathrm{~V}$ the average emissions of $\mathrm{CO}$ and $\mathrm{HC} 95.5 \mathrm{ppm} 0.187 \%$. At a voltage of $11 \mathrm{~V}$ emissions down to $0.125 \% \mathrm{CO}$ and HC 62.5ppm. However, when the voltage is $10 \mathrm{~V}$ and $9 \mathrm{~V}$ increased emissions. At $10 \mathrm{~V}$ variation 0.245\% CO and HC 110.8ppm. At 9 V variation 0.303\% CO and HC 139.2ppm.
\end{abstract}

Keywords : Fuel Pumps, Exhaust Emissions

\section{PENDAHULUAN}

Perkembangan Ilmu Pengetahuan dan Teknologi (IPTEK) di bidang otomotif terus mengalami peningkatan. Menurut catatan Kementrian Perindustrian, nilai investasi di sektor komponen otomotif mencapai US\$ 4 miliar. Selain itu Data Gabungan Industri Kendaraan Bermotor Indonesia memperlihatkan ekspor komponen otomotif selama 7 bulan terakhir naik $8,8 \%$ dari 29,5 juta bagian pada periode yang sama tahun lalu menjadi 32,1 juta bagian.

Kapasitas produksi komponen akan bertambah dengan diresmikannya pabrik milik PT Unipres Indonesia, perusahaan afiliasi Marubeni Corporation, seluas 8 hektare di Cikampek, Karawang, Jawa
Barat, pada akhir bulan lalu (Berita Industri, http://www.kemenperin.go.id).

Pertumbuhan jumlah kendaraan yang semakin meningkat secara langsung dapat mencerminkan pertumbuhan ekonomi saat ini. Dapat dilihat pada saat ini setiap rumah tangga bisa dikatakan memiliki satu jenis kendaraan pribadi bahkan lebih dari satu kendaraan, baik itu mobil ataupun sepeda motor. Perkembangan kendaraan bermotor dari tahun ke tahun terus mengalami peningkatan. Berdasarkan data dari Kantor Kepolisian Republik Indonesia jumlah kendaraan bermotor pada tahun 2012 mencapai 94 juta. Data perkembangan jumlah kendaraan bermotor menurut jenis kendaraan dari tahun 2008 sampai 2012 dapat dilihat pada tabel 1 . 
Tabel 1. Perkembangan Jumlah Kendaraan Bermotor

\begin{tabular}{|c|c|c|c|c|c|}
\hline \multicolumn{6}{|c|}{ Perkembangan Jumlah Kendaraan Bermotor Menurut Jenis Kendaraan } \\
\hline Tahun & $\begin{array}{c}\text { Mobil } \\
\text { Penumpang }\end{array}$ & Bis & Truk & $\begin{array}{c}\text { Sepeda } \\
\text { Motor }\end{array}$ & Jumlah \\
\hline 2008 & 7.489 .852 & 2.059 .187 & 4.452 .343 & 47.683 .681 & 61.685 .063 \\
\hline 2009 & 7.910 .407 & 2.160 .973 & 4.452 .343 & 52.767 .093 & 67.336 .644 \\
\hline 2010 & 8.891 .041 & 2.250 .109 & 4.687 .789 & 61.078 .188 & 76.907 .127 \\
\hline 2011 & 9.548 .866 & 2.254 .406 & 4.958 .738 & 68.839 .341 & 85.601 .351 \\
\hline 2012 & 10.432 .259 & 2.273 .821 & 5.286 .061 & 76.381 .183 & 94.373 .324 \\
\hline
\end{tabular}

Selain itu dampak dari pencemaran udara dapat menyebabkan pengikisan lapisan ozon, menimbulkan hujan asam, kerusakan tanaman, dan dapat mempercepat empat kali lebih cepat proses pengaratan pada benda-benda yang terbuat dari besi. Pencemaran udara ini juga dapat menyababkan kerusakan lingkungan lebih jauh yaitu menimbulkan efek rumah kaca yang akan menaikkan suhu permukaan bumi atau dikenal dengan istilah global warming. Hal ini akan menyebabkan permukaan air laut akan naik disebabkan es di kutup akan mencair. Global warming juga berdampak pada perubahan iklim di bumi yang akan menimbulkan kekeringan dan banjir di seluruh dunia sehingga akan berdampak buruk terhadap persediaan pangan dunia.

Menteri Dalam Negeri mengatakan "berdasarkan hasil evaluasi Kementerian Lingkungan Hidup sesuai surat Menteri
Lingkungan Hidup Nomor B/38X/MENLH/PDAL/12/2013, telah terjadi penurunan kualitas udara perkotaan, dimana $90 \%$ di antaranya merupakan kontribusi polusi udara dari sektor transportasi, khususnya dari emisi gas buang kendaraan bermotor" (http://setkab.go.id). Tabel 2 menunjukkan data sumber pencemaran udara di Indonesia.

Hasil penelitian yang dilakukan oleh Kementerian Lingkungan Hidup tahun 2012 di beberapa kota di Indonesia menunjukkan bahwa terdapat emisi gas buang $\mathrm{HC}$ diatas baku mutu gas buang yang telah ditetapkan. Salah satunya adalah Kota Padang, tercatat pada tahun 2011 konsentrasi gas HC mencapai 200 $\mathrm{ug} / \mathrm{Nm}^{3}$ dan pada tahun 2012 mengalami peningkatan menjadi $210 \mathrm{ug} / \mathrm{Nm}^{3}$.

Tabel 2. Jenis Sumber Polusi Udara di Indonesia

\begin{tabular}{lcccccc}
\hline \multicolumn{1}{c}{ Sumber } & \multicolumn{7}{c}{ Polusi (Dalam Juta Ton/Tahun) } \\
& CO & Part & Sox & HC & NOx & Total \\
\hline Transportasi & 63.8 & 1.2 & 0.8 & 16.6 & 8.1 & 90.5 \\
Pembakaran Stasioner & 1.9 & 8.9 & 24.4 & 0.7 & 10.0 & 45.9 \\
Proses Industri & 9.7 & 7.5 & 7.3 & 4.6 & 0.2 & 29.3 \\
Pembuangan Sampah & 7.8 & 1.1 & 0.1 & 1.6 & 0.6 & 11.2 \\
Lain (k. hutan, pertanian) & 16.9 & 9.6 & 0.6 & 8.5 & 1.7 & 37.3 \\
Total & 100.1 & 28.3 & 33.2 & 32 & 20.6 & 214.2
\end{tabular}


Tabel 3. Konsentrasi Gas HC di Beberapa Kota di Indonesia

\begin{tabular}{clcc}
\hline \multirow{2}{*}{ No } & \multicolumn{1}{c}{ Kota } & $\mathbf{2 0 1 1}$ & $\mathbf{H C}\left(\mathbf{u g} / \mathbf{N m}^{\mathbf{3}}\right)$ \\
& & 250 & 220 \\
\hline 1 & Balikpapan & 185 & 175 \\
2 & Bandar Lampung & 180 & 180 \\
3 & Batam & 305 & 225 \\
4 & Makasar & $\mathbf{2 0 0}$ & $\mathbf{2 1 0}$ \\
$\mathbf{5}$ & Padang & 315 & 220 \\
6 & Pekanbaru & 315 & 200 \\
7 & Semarang & 140 & 195 \\
8 & Surakarta & & 160
\end{tabular}

Tabel 4. Data Pencemaran Udara di Provinsi Sumatra Barat Tahun 2014

\begin{tabular}{llllccc}
\hline \multicolumn{1}{c}{ Sumber } & \multicolumn{5}{c}{ Jumlah Komponen Pencemar (Juta ton/tahun) } \\
& Nox & Sox & HC & Partikulat & CO & Total \\
\hline Transportasi & 8.1 & 0.8 & 16.6 & 1.2 & 74.99 & 90.5 \\
Industri & 0.2 & 7.3 & 4.6 & 7.5 & 7.8 & 29.3 \\
Pembuangan sampah & 0.6 & 0.1 & 1.6 & 1.1 & 1.3 & 11.2 \\
Pembakaran stasioner & 10.0 & 24.4 & 0.7 & 8.9 & 9.1 & 45.9 \\
Lain-lain & 1.7 & 0.6 & 8.5 & 9.6 & 9.9 & 37.3
\end{tabular}

Secara keseluruhan konsentrasi gas HC dibeberapa kota besar di Indonesia dapat dilihat pada tabel 3.

Data terakhir pada tahun 2014 tentang pencemaran udara di wilayah Provinsi Sumatera Barat menunjukkan bahwa, pencemaran udara yang bersumber dari sektor transportasi merupakan jumlah terbesar dibandingkan dengan sumber lainnya yaitu sebesar 90,5. Data pencemaran udara di wilayah Provinsi Sumatera Barat tahun 2014 dapat di lihat pada tabel 4.

Perkembangan teknologi otomotif saat ini lebih diarahkan pada upaya pengendalian dampak emisi dan pengurangan kadar emisi gas buang yang dihasilkan dari gas sisa pembakaran. Pemerintah telah mewajibkan produsen kendaraan bermotor menggunakan standar EURO 3 dan pemerintah juga membuat suatu kebijakan tentang nilai ambang batas emisi gas buang kendaraan bermotor. Hal ini terdapat dalam Peraturan Menteri Negara Lingkungan Hidup Nomor 04 Tahun 2009 tentang
Ambang Batas Emisi Gas Buang Kendaraan Bermotor Tipe Baru. Pemerintah berharap dengan adanya standar perbaikan dari segi teknologi tersebut diharapkan dapat berkontribusi terhadap penurunan polusi udara yang disebabkan emisi gas buang kendaraan.

Perkembangan teknologi otomotif langsung menanggapi hal tersebut, ditandai dengan adanya beberapa penambahan sistem pada kendaraan bermotor atau mobil. Salah satunya yang paling populer saat ini adalah dengan mengaplikasikan sistem EFI (Electronic Fuel Injection) pada sistem bahan bakar kendaraan bermotor. Sebenarnya sistem ini bukanlah teknologi baru, sistem ini sudah ditemukan sejak tahun 1925 oleh insinyur yang berasal dari Swedia bernama Jonas Hesselman (Wahyu, 2012:108). Mesin ciptaannya dikenal dengan nama mesin Hesselman, yang kemudian digunakan pada mesin diesel dan bensin. Merk yang menggunakan mesin injeksi pada masa itu adalah Scania-Vabis, Tidaholms Bruk dan Volvo. 
Kendaraan yang menggunakan sistem EFI, penyemprotan bahan bakar diatur oleh komputer disebut ECU (Electronic Control Unit). ECU ini mengontrol jumlah bahan bakar yang akan diinjeksikan ke ruang bakar lebih akurat dibandingkan dengan sistem biasa (karburator), sehingga mampu menghasilkan emisi gas buang (exhaust emission) yang lebih bersih dan mampu menghemat konsumsi bahan bakar.

Hasil pengujian Kementerian Negara Lingkungan Hidup pada tahun 2013 menunjukkan, jika dibandingkan dengan baku mutu emisi gas buang kendaraan bermotor tipe baru yang diatur dalam Peraturan Menteri Negara Lingkungan Hidup Nomor 04 Tahun 2009 tentang Ambang Batas Emisi Gas Buang Kendaraan Bermotor Tipe Baru menunjukkan masih terdapat emisi gas CO berada di atas baku mutu emisi gas buang yang ditetapkan (http://www.menlh.go.id).

Pompa bahan bakar merupakan komponen yang sangat penting dalam sistem injeksi. Fungsi utama pompa bahan bakar adalah untuk memompa, mengalirkan dan menyuplai bahan bakar dengan menghasilkan tekanan yang siap diinjeksikan. Pompa bahan bakar akan bekerja apabila ECU telah mengaktifkan relay pompa, kemudian arus listrik dari baterai mengalir ke pompa bahan bakar dan pompa akan berkerja. Besarnya tegangan yang ada pada pompa bahan bakar akan sama dengan tegangan yang ada pada baterai. Pompa bahan bakar pada sistem EFI adalah pompa yang menggunakan motor listrik sehingga putaran dan tekanan bahan bakar yang dihasilkan tinggi.

Pompa bahan bakar akan terus bekerja dengan putaran yang tinggi sesuai besarnya tegangan yang ada pada baterai. Pompa bahan bakar selalu bekerja pada putaran yang tinggi dapat menyebabkan brush pada pompa akan cepat habis sehingga kerja pompa akan menjadi berkurang bahkan pompa akan menjadi rusak. Pompa bahan bakar yang rusak merupakan salah satu penyebab terjadinya masalah pada engine mobil EFI. Kerusakan pompa bahan bakar disebabkan karena rendahnya volume bahan bakar (fuel low level), dengan mengendarai kendaran dengan fuel low level secara permanen atau terlalu sering dapat menyebabkan kerusakan pompa. Ketika bahan bakar dalam keadaan low level, pompa harus bekerja lebih keras untuk mengasilkan tekanan bahan bakar yang sama. Karena berat bahan bakar telah berkurang untuk mendorong bahan bakar ke pompa, maka pompa harus menarik bahan bakar dari dalam tangki tersebut. Rendahnya volume bahan bakar di dalam tangki tidak mampu mendinginkan pompa yang telah bekerja terlalu keras, maka kemungkinan pompa akan menjadi rusak.

Sesuai dengan fungsinya pompa bahan bakar akan mempengaruhi besarkecilnya tekanan bahan bakar. Perubahan tekanan bahan bakar berpengaruh terhadap proses pencampuran udara dan bahan bakar didalam intake manifold. Apabila pompa bahan bakar tidak dapat bekerja normal maka akan mempengaruhi idealnya campuran udara dan bahan bakar. Pulkrabek (2004: 332) mengatakan, "apabila terjadi campuran kaya dan campuran kurus ataupun campuran terlalu kurus akan menyebabkan terjadinya peningkatan kadar emisi gas buang $\mathrm{CO}$ dan HC".

Berdasarkan data pada tabel 4, tentang pencemaran udara di Provinsi Sumatera Barat tahun 2014 yang menunjukkan bahwa $\mathrm{CO}$ dan $\mathrm{HC}$ merupakan penyumbang terbesar pencemaran udara dari sektor transportasi. Berdasarkan hal tersebut maka penelitian ini lebih ditujukan untuk mengetahui kadar CO dan HC pada kendaraan yang digunakan untuk penelitian ini, yakni mobil Toyota Avanza 1.3 G M/T.

Penelitian ini ditujukan untuk mengetahui besar-kecilnya pengaruh 
variasi tegangan listrik $(9 \mathrm{~V}, 10 \mathrm{~V}, 11 \mathrm{~V}$ dan $12 \mathrm{~V}$ ) pompa bahan bakar terhadap kadar emisi gas buang dari tipe mobil yang sama. Data dari hasil penelitian ini nantinya akan disesuaikan dengan standart emisi gas buang yang ada.

\section{Emisi Gas Buang}

Emisi gas buang merupakan suatu zat yang dihasilkan dari proses pembakaran motor bensin yang dapat menyebabkan terjadinya pencemaran udara. Wardan (1989: 135) menjelaskan bahwa "Emisi gas buang adalah polutan yang mengotori udara yang dihasilkan dari gas buang kendaraan" [5].

Menurut Wisnu (2004: 31) "Zat pencemar lingkungan yang paling banyak berpengaruh dalam pencemaran udara adalah: Karbon Monoksida (CO), Nitrogen Oksida (NOx), Belerang Oksida (Sox), Hidrokarbon (HC), dan pertikelpartikel'[7]. Zat pencemar udara yang dibahas dalam penelitian ini adalah Karbon Monoksida (CO) dan Hidrokarbon (HC).

Tabel 5. Pengaruh Konsentrasi CO di Udara dan Pengaruhnya pada Tubuh Bila Kontak Terjadi pada Waktu yang Lama

\begin{tabular}{ccl}
\hline $\begin{array}{c}\text { Konsentrasi CO di } \\
\text { Udara (ppm) }\end{array}$ & $\begin{array}{c}\text { Konsentrasi COHb di dalam } \\
\text { Darah (\%) }\end{array}$ & Gangguan pada Tubuh \\
\hline 3 & 0,98 & Tidak ada \\
5 & 1,3 & Belum begitu terasa \\
10 & 2,1 & Sistem syaraf sentral \\
20 & 3,7 & Panca indera \\
40 & 6,9 & Fungsi jantung \\
60 & 10,1 & Sakit kepala \\
80 & 13,3 & Sulit bernafas \\
100 & 16,5 & Pingsan-kematian
\end{tabular}

(Sumber: Wisnu, 2004: 120) 


\section{Karbon Monoksida (CO)}

Wisnu (2004: 41) menyatakan bahwa "Karbon Monoksida (CO) adalah suatu gas yang tidak berwarna, tidak berbau dan juga tidak berasa" [7]. Munculnya gas CO dalam proses pembakaran disebabkan karena campuran udara dan bahan bakar yang tidak sempurna.

Toyota (1972: 2-10), menambahkan bahwa "Gas CO dapat bercampur dengan hemoglobin yang terdapat dalam darah menjadi Carboksi Hemoglobin (CO-Hb)" [6]. Kekurangan oksigen dalam aliran darah dan jaringan tubuh akan menurunkan kinerja tubuh dan pada akhirnya dapat menimbulkan kerusakan pada organ-organ tubuh manusia

\section{Hidrokarbon ( HC)}

Wisnu (2004: 115) menjelaskan bahwa "Dinamakan Hidrokarbon karena penyusun utamanya adalah atom karbon dan atom Hidrogen yang dapat terikat (tersusun) secara ikatan lurus (ikatan rantai) atau terikat secara ikatan cincin (ikatan tertutup)"[7].

Hidrokarbon dihasilkan dari bahan bakar yang tidak terbakar saat proses pembakaran. Emisi hidrokarbon memiliki sifat berbau, mudah menguap, dan bereaksi lebih lanjut dengan NOx menjadi senyawa fotokimia dan dapat menyebabkan hujan asam. Senyawa fotokimia yang terbentuk dari emisi HC dapat mengakibatkan mata pedih, sakit tenggorokan, dan gangguan pernafasan. Hidrokarbon juga bersifat carcinogens atau dapat menyebabkan kanker.

\section{Pompa Bahan Bakar}

Menurut Wahyu (2012: 118) mengatakan bahwa "Fuel pump mengalirkan dan menyuplai bahan bakar dengan menghasilkan tekanan yang siap disemprotkan/diinjeksikan" [3].

Sementara itu menurut Brady, Robert N (2001: 260) "The electric fuel pump is a component of the MFSA (Modular Fuel Sender Assembly) that is inserted into the fuel tank typically from the top through a 4" (102.4mm). The fuel is drawn into an internal, self-filling recervoir through the stainer" [2].

Menurut Wardan (1989: 142) mengatakan bahwa "Di dalam sistem bahan bakar digunakan pompa bahan bakar untuk mengalirkan bahan bakar dari tangki ke karburator atau ke sistem injeksi bahan bakar, karena letak tangki bahan bakar lebih rendah dibanding letak karburator" [5].

Tekanan bahan bakar yang dihasilkan oleh pompa bahan bakar dapat mencapai 3,19 s/d $329 \mathrm{kPa}$ setara dengan $3,3 \mathrm{~s} / \mathrm{d} 3,4 \mathrm{kgf} / \mathrm{cm}^{2}$ (46 s/d $48 \mathrm{psi}$ ) pada mobil Toyota Avanza.

Kapasitas pemompaan bensin oleh pompa bahan bakar harus melebihi kebutuhan/pemakaian bensin maksimum, dengan demikian selalu ada bensin yang mengalir kembali ke tangki, sirkulasi seperti ini diperlukan oleh sistem bahan bakar untuk selalu memperoleh bensin dingin selama proses kerja agar gelembunggelembung uap yang terbentuk dalam aliran bahan bakar dapat dihindari.

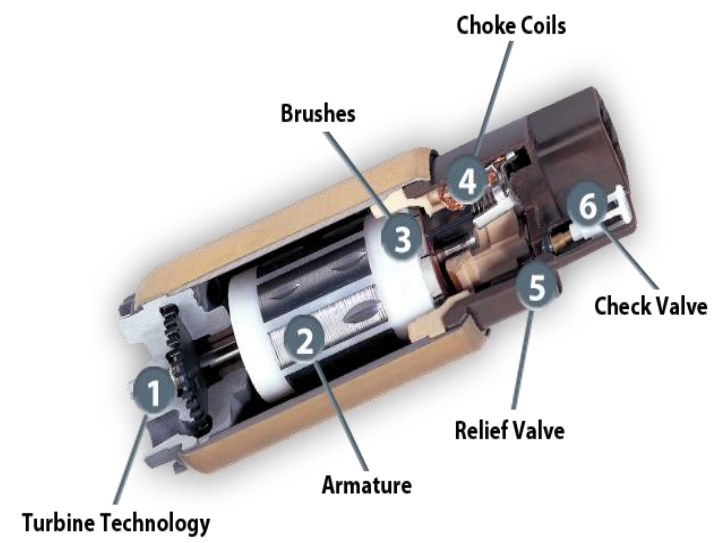

Gambar 1. Konstruksi Pompa

(Sumber: www.densoautopart.com)

Komponen utama pompa bahan bakar yang memiliki peranan yang sangat penting adalah motor, check valve, dan relief valve.

1) Motor

Motor pompa bahan bakar terdiri dari brush, armature dan magnet. Motor pompa berfungsi untuk menghasilkan tekanan 
bahan bakar yang akan disalurkan ke dalam sistem bahan bakar.

\section{2) Relief valve}

Relief valve berfungsi untuk mencegak naiknya tekanan bahan bakar dari batas yang telah ditentukan. Relief valve bekerja jika terjadi gangguan pada sisi discharge dan pengeluaran bahan bakar terhambat, tekanan di dalam pompa akan semakin tinggi di atas batas normal. Ketika tekanan di dalam pompa mencapai 3,5 sampai $6,0 \mathrm{~kg} / \mathrm{cm}^{2}$, relief valve akan terbuka untuk melepaskan tekanan, sehingga mencegah naiknya tekanan bahan bakar melampaui batas tekanan yang ditentukan.

\section{3) Check valve}

Check valve berfungsi untuk menjaga agar di dalam saluran bahan bakar terdapat sisa tekanan apabila engine mati, sehingga mempermudah kerja pompa saat engine di hidupkan kembali. Ketika pompa berhenti bekerja, check valve akan tertutup untuk mempertahankan tekanan yang tinggi di dalam saluran-saluran bahan bakar. Penahanan tekanan tinggi di saluran-saluran bahan bakar disini akan memberikan kemudahan untuk menghidupkan engine kembali dan juga untuk mencegah vapor lock pada temperatur tinggi.

\section{Power Supply}

Power supply adalah alat atau perangkat keras yang mampu menyuplai tegangan listrik secara langsung dari sumber tegangan listrik ke tegangan listrik yang lainnya. Sugiri (2004: 43) menambahkan bahwa "Power supply merupakan komponen yang berfungsi memberikan tenaga kepada semua komponen komputer agar dapat berfungsi" [4].

Berdasarkan fungsinya, Power supply dapat dibedakan menjadi Regulated Power Supply, Unregulated Power Supply dan Adjustable Power Supply.

Regulated Power Supply adalah Power Supply yang dapat menjaga kestabilan tegangan dan arus listrik meskipun terdapat perubahaan atau variasi pada beban atau sumber listrik (tegangan dan arus input).

Unregulated Power Supply adalah Power Supply tegangan ataupun arus listriknya dapat berubah ketika beban berubah atau sumber listriknya mengalami perubahan.

Adjustable Power Supply adalah Power Supply yang tegangan atau arusnya dapat diatur sesuai kebutuhan.

Penelitian ini mengunakan Power Supply jenis Adjustable Power Supply, pada penelitian ini yang akan divariasikan adalah tegangan listrik pompa bahan bakar. Beberapa komponen yang digunakan pada rangkaian ini adalah; dioda, saklar dan voltmeter. Bentuk rangkaian Power Supply tersebut adalah seperti pada gambar di bawah ini.

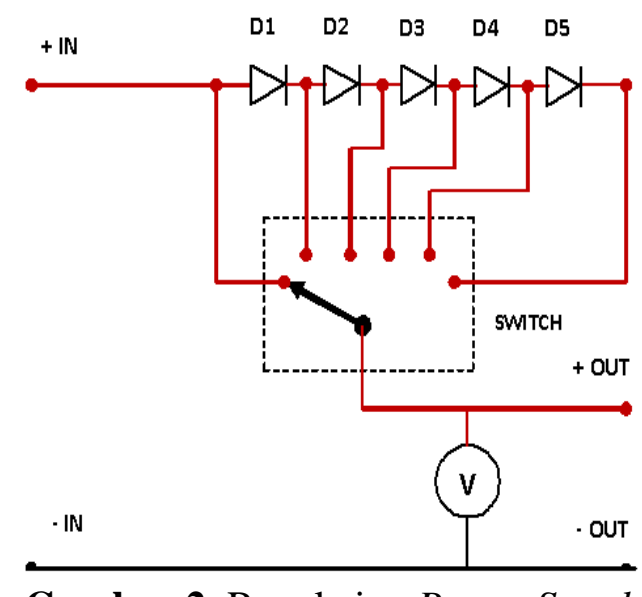

Gambar 2. Rangkaian Power Supply

\section{METODOLOGI}

Penelitian ini mengunakan metode eksperimen, Suharsimi (1990: 272) mengatakan bahwa "Penelitian eksperimen dimaksudkan untuk mengetahui ada tidaknya akibat dari sesuatu yang dikenakan pada subjek selidik" [1].

Penelitian ini dimaksudkan untuk mengetahui dan membuktikan adanya pengaruh variasi tegangan listrik pompa bahan bakar terhadap emisi gas buang pada mobil Toyota avanza $1.3 \mathrm{G} \mathrm{M} / \mathrm{T}$.

Penelitian ini dilakukan dengan memvariasikan tegangan listrik pompa bahan bakar $(9 \mathrm{~V}, 10 \mathrm{~V}, 11 \mathrm{~V}$ dan $12 \mathrm{~V})$ dan 
menggunakan putaran engine (800, 1500 dan $3000 \mathrm{rpm}$ ) untuk masing-masing tegangan pompa bahan bakar pada satu jenis mobil yang sama.

Objek penelitian dalam penelitian ini adalah kadar emisi gas buang yang dihasilkan oleh mobil Toyota Avanza $1.3 \mathrm{G}$ $\mathrm{M} / \mathrm{T}$. Dalam penelitian ini, data yang akan diambil yaitu kadar emisi gas buang yang diperoleh dari memvariasikan tegangan listrik pada pompa bahan bakar mobil Toyota Avanza 1.3 G M/T.

Jenis data yang digunakan dalam penelitian ini adalah data primer dan data sekunder. Data primer adalah data yang diperoleh secara langsung pada saat melakukan pengujian, yaitu kadar emisi gas buang. Sedangkan data sekunder adalah data yang mempunyai hubungan dengan topik penelitian yang diperoleh dari sejumlah referensi sebagai data penguat penelitian.

Teknik pengumpulan data dalam penelitian ini adalah dengan melakukan pengambilan data secara langsung pada objek penelitian yang sedang diuji dengan menggunakan beberapa instrumen penelitian tersebut. Sedangkan alat pengumpulan data yang digunakan berupa tabel-tabel hasil pengujian yang selanjutnya akan diolah, sehingga menghasilkan grafik presentase kadar emisi gas buang pada pengujian. Hasil pengujian dilakukan dengan membandingkan kadar emisi gas buang yang diperoleh dari variasi tegangan listrik pompa bahan bakar $(9 \mathrm{~V}, 10 \mathrm{~V}, 11 \mathrm{~V}$ dan $12 \mathrm{~V})$.

HASIL

Tabel 5. Hasil Pengujian Kandungan Emisi Gas Buang CO

\begin{tabular}{|c|c|c|c|c|}
\hline \multirow{2}{*}{$\begin{array}{c}\text { Variasi } \\
\text { Tegangan }\end{array}$} & \multirow{2}{*}{$\begin{array}{c}\text { Putaran } \\
\text { (RPM) }\end{array}$} & \multicolumn{3}{|c|}{ Kadar HC (ppm) } \\
\cline { 3 - 5 } & & \multicolumn{2}{|c|}{ Pengujian } & \multirow{2}{*}{ Rerata } \\
\hline \multirow{4}{*}{$12 \mathrm{~V}$} & 800 & 163 & 164 & 163.5 \\
\cline { 2 - 5 } & 1500 & 84 & 81 & 82.5 \\
\cline { 2 - 5 } & 3000 & 39 & 42 & 40.5 \\
\cline { 2 - 5 } & & & & 95.5 \\
\hline \multirow{4}{*}{$11 \mathrm{~V}$} & 800 & 91 & 85 & 88.0 \\
\cline { 2 - 5 } & 1500 & 45 & 46 & 45.5 \\
\cline { 2 - 5 } & 3000 & 53 & 55 & 54.0 \\
\cline { 2 - 5 } & & & & 62.5 \\
\hline \multirow{4}{*}{$10 \mathrm{~V}$} & 800 & 151 & 148 & 149.5 \\
\cline { 2 - 5 } & 1500 & 121 & 121 & 121.0 \\
\cline { 2 - 5 } & 3000 & 63 & 61 & 62.0 \\
\cline { 2 - 5 } & & & & 110.8 \\
\hline \multirow{4}{*}{$9 \mathrm{~V}$} & 800 & 144 & 142 & 143.0 \\
\cline { 2 - 5 } & 1500 & 159 & 158 & 158.5 \\
\cline { 2 - 5 } & 3000 & 119 & 113 & 116.0 \\
\cline { 2 - 5 } & & & & 139.2 \\
\hline
\end{tabular}

Tabel 6. Hasil Pengujian Kandungan Emisi Gas Buang HC

\begin{tabular}{|c|c|c|c|c|}
\hline \multirow{2}{*}{$\begin{array}{c}\text { Variasi } \\
\text { Tegangan }\end{array}$} & \multirow{2}{*}{$\begin{array}{c}\text { Putaran } \\
\text { (RPM) }\end{array}$} & \multicolumn{3}{|c|}{ Kadar CO (\%) } \\
\cline { 3 - 5 } & & \multicolumn{2}{|c|}{ Pengujian } & \multirow{2}{*}{ Rerata } \\
\cline { 2 - 5 } $12 \mathrm{~V}$ & 800 & 0.36 & 0.36 & 0.360 \\
\cline { 2 - 5 } & 1500 & 0.08 & 0.09 & 0.085 \\
\cline { 2 - 5 } & 3000 & 0.13 & 0.10 & 0.115 \\
\cline { 2 - 5 } & & & & 0.187 \\
\hline \multirow{4}{*}{$11 \mathrm{~V}$} & 800 & 0.25 & 0.28 & 0.265 \\
\cline { 2 - 5 } & 1500 & 0.05 & 0.08 & 0.065 \\
\cline { 2 - 5 } & 3000 & 0.03 & 0.06 & 0.045 \\
\cline { 2 - 5 } & & & & 0.125 \\
\hline \multirow{4}{*}{$9 \mathrm{~V}$} & 800 & 0.31 & 0.31 & 0.310 \\
\cline { 2 - 5 } & 1500 & 0.26 & 0.30 & 0.280 \\
\cline { 2 - 5 } & 3000 & 0.17 & 0.12 & 0.145 \\
\cline { 2 - 5 } & & & & 0.245 \\
\hline \multirow{4}{*}{$9 \mathrm{~V}$} & 800 & 0.33 & 0.32 & 0.325 \\
\cline { 2 - 5 } & 1500 & 0.43 & 0.40 & 0.415 \\
\cline { 2 - 5 } & 3000 & 0.16 & 0.18 & 0.170 \\
\cline { 2 - 5 } & & & & 0.303 \\
\hline
\end{tabular}

\section{PEMBAHASAN}

\section{Analisa Grafik}

Data tabel 5 dan 6 di atas apabila digrafikkan diperoleh grafik seperti pada gambar 3 dan 4.

Ditemukan fakta bahwa tegangan 11 Volt memberikan nilai yang paling baik daripada variasi tegangan lainnya. 


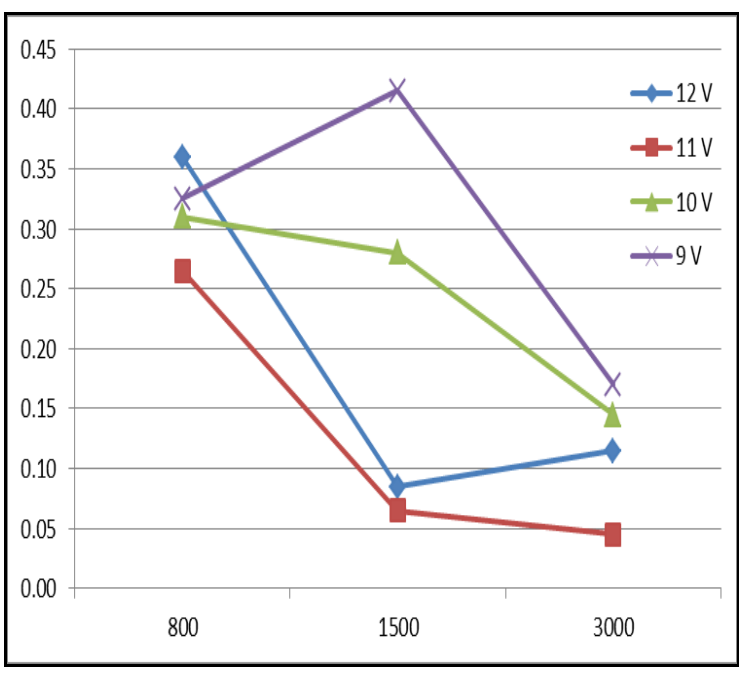

Gambar 3. Grafik perbandingan $\mathrm{CO}$

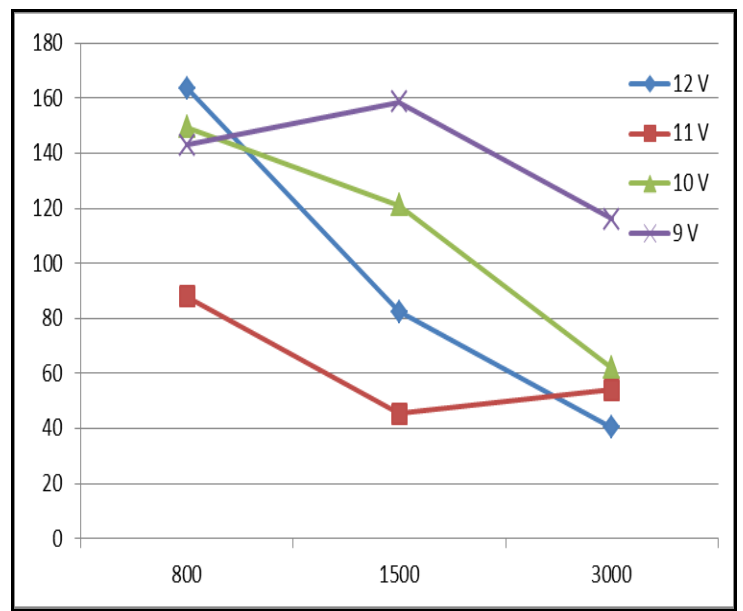

Gambar 4. Grafik perbandingan HC

\section{Analisa Statistik}

Berdasarkan tujuan dari penelitian ini, yaitu untuk mengetahui seberapa besar pengaruh variasi tegangan listrik pompa bahan bakar terhadap emisi gas buang pada mobil Toyota Avanza 1,3 G M/T. Untuk melihat seberapa besar pengaruh dari variasi tegangan listrik pompa bahan bakar, maka perlu dilakukan analisis persentase perubahan kadar emisi gas buang $\mathrm{CO}$ dan HC.

Berdasarkan hasil analisis persentase diketahui bahwa dengan variasi tegangan 11 volt terjadi penurunan kadar emisi gas buang CO sebesar $33 \%$. Variasi tegangan 10 volt terjadi kenaikkan kadar emisi gas buang CO sebesar $31 \%$. Kemudian dengan variasi tegangan 9 volt terjadi kenaikkan kadar emisi gas buang sebesar $63 \%$.
Variasi tegangan 11 volt terjadi penurunan kadar emisi gas buang $\mathrm{HC}$ sebesar $35 \%$. Variasi tegangan 10 volt terjadi kenaikkan kadar emisi gas buang HC sebesar $16 \%$. Kemudian pada variasi tegangan 9 volt terjadi kenaikkan kadar emisi gas buang $\mathrm{HC}$ sebesar $46 \%$.

Perubahan kadar emisi gas buang pada kendaraan juga disebabkan oleh berubahnya tegangan pompa bahan bakar. Hal tersebut dapat terjadi karena pada sistem EFI (Electronic Fuel Injection) pompa bahan bakar sangat berperan penting yaitu menyalurkan bahan bakar dengan tekanan tinggi ke dalam saluran bahan bakar. Sehingga pada saat terjadi perubahan tegangan pada pompa bahan bakar, maka putaran pompa akan berubah dan tekanan bahan bakar yang dihasilkannya menjadi berubah. Tekanan bahan bakar tersebut akan mempengaruhi debit dan waktu penginjeksian bahan bakar. Sehingga akan mempengaruhi campuran udara dan bahan bakar yang dihasilkan, maka emisi gas buang yang dihasilkan juga akan berubah.

Hal ini sesuai dengan teori Pulkrabek (2004), yaitu apabila jumlah bahan bakar yang bercampur dengan udara lebih banyak maka emisi gas buang $\mathrm{CO}$ dan $\mathrm{HC}$ akan meningkat. Sebaliknya apabila putaran mesin tinggi (> 3000rpm untuk Avanza) akan menyebabkan terjadinya kevakuman yang tinggi pada intake manifold. Hal ini menyebabkan jumlah udara yang bercampur dengan bahan bakar lebih banyak atau campuran kurus, maka $\mathrm{CO}$ dan HC berkurang. Pulkrabel (2004) menambahkan, apabila campuran udara dan bahan bakar terlalu kurus maka emisi gas buang HC akan meningkat secara mendadak.

\section{SIMPULAN}

Hasil penelitian menunjukkan bahwa variasi tegangan pompa bahan bakar dapat berpengaruh pada kandungan emisi gas buang.

Tegangan 11 volt memberikan kualitas emisi yang paling baik 
dibandingkan dengan tegangan $12 \mathrm{~V}, 10 \mathrm{~V}$ dan $9 \mathrm{~V}$.

\section{SARAN}

Penelitian ini masih terbatas hanya pada beberapa variasi tegangan dan putaran mesin saja, sehingga pada penelitian lebih lanjut agar dapat dilakukan variasi tegangan dan putaran yang lebih bervariasi lagi.

Sebaiknya pada penelitian lebih lanjut perlu dilakukan penelitian dengan menggunakan mobil dengan kapasitas engine yang berbeda. Penelitian ini masih terbatas hanya pada pengaruh terhadap kadar emisi gas buang CO dan HC saja, pada penelitian lanjutan agar dilakukan pada pengaruh konsumsi bahan bakar dan emisi lainnya.

\section{DAFTAR PUSTAKA}

[1] Arikunto, Suharsimi. 1990. Manajemen Penelitian. Jakarta: Rineka Cipta.

[2] Brady, Robert N. 2001. Automotive Electronics and Computer Systems. New Jersey Columbus, Ohio: Prentice Hall.

\3] Hidayat, Wahyu. 2012. Motor Bensin Modern. Jakarta: Rineka Cipta.

[4] Sugiri. 2004. Elektronika Dasar. Yogyakarta: CV. Andi Offset.

[5] Suyanto, Wardan. 1989. Teori Motor Bensin. Jakarta: P2LPTK.

[6] Toyota. 1972. Engine Group Step 2. Jakarta: PT. Toyota Astra Motor.

[7] Wardhana, Wisnu Arya. 2004. Dampak Pencemaran Lingkungan.

Yogyakarta: CV. Andi Ofset. 